\title{
Breeding success and juvenile survival in a reintroduced captive-bred population of Asian houbara bustards in the United Arab Emirates
}

\author{
Joseph F. Azar ${ }^{1, *}$, Toni Chalah ${ }^{2}$, Pierrick Rautureau ${ }^{2}$, Mark Lawrence ${ }^{2}$, \\ Yves Hingrat ${ }^{1}$
}

${ }^{1}$ Reneco International Wildlife Consultants, LLC, Abu Dhabi, United Arab Emirates
${ }^{2}$ National Avian Research Centre, Sweihan, Abu Dhabi, United Arab Emirates

\begin{abstract}
Identifying factors influencing breeding success in endangered species is vital for undertaking appropriate conservation measures. The reintroduced population of the captive-bred Asian houbara bustard Chlamydotis macqueenii in reserves of the western United Arab Emirates (UAE) has been closely monitored since releases first began in 2005. Based on $8 \mathrm{yr}$ of monitoring data, we provide novel information on female breeding probability and breeding success within a desert ecosystem. Additionally, we explore factors influencing some breeding parameters. Female breeding probability was on average $0.14 \pm 0.31 \mathrm{SD}(0.01 \pm 0.03$ for females less than $1 \mathrm{yr}$ old and $0.23 \pm 0.38$ for females older than $1 \mathrm{yr}$ ). Nest initiation date was influenced by temperature and time. Rainfall during a breeding season increased its length. The estimated nest survival rate for $23 \mathrm{~d}$ was 0.52 , and was negatively influenced by nest initiation date. Chick survival rate to the age of 6 wk was $0.50 \pm 0.39 \mathrm{SD}$, and survival rate of juveniles in their first year was $0.64 \pm 0.02 \mathrm{SE}$. Our results highlight the ability of captive-bred released houbara in the UAE to breed and of wild born juveniles to survive, 2 vital prerequisites for a successful reintroduction programme. Furthermore, these breeding parameters are similar to the very few that have been reported in other studies of wild resident houbara populations. However, population recruitment rate was low (0.04 individuals per female), resulting mainly from low female breeding probability under harsh weather conditions.
\end{abstract}

KEY WORDS: Chlamydotis macqueenii - Breeding parameters - Captive breeding $\cdot$ Recruitment · Survival $\cdot$ Translocation $\cdot$ RMark

\section{INTRODUCTION}

Reintroduction is an important conservation tool to restore populations of endangered species (Seddon et al. 2012, IUCN 2013). The ultimate goal of a reintroduction programme is achieved when translocated animals are able to survive in the long term and reproduce successfully at rates resulting in positive population growth enabling viability (Rout et al. 2009, Schaub et al. 2009). Therefore, for reintroduced populations, knowledge of breeding parameters and key drivers of breeding success are essential to pro-

\footnotetext{
*Corresponding author: azar.joseph@gmail.com
}

vide guidance for appropriate conservation strategies (Sutherland 1996). This is especially true when reintroduced individuals are captive-bred, and the knowledge from former wild population is scarce (Parker et al. 2012).

The Asian houbara Chlamydotis macqueenii (hereafter 'houbara') is a medium-sized bustard species adapted to arid and semi-arid ecosystems (Hoyo et al. 1996, Van Heezik \& Seddon 1999, Riou \& Combreau 2014). It is resident in the southern extent of its range (from the Arabian Peninsula to southern Central Asia), but migratory in most of Central Asia and parts

() The authors 2018. Open Access under Creative Commons by Attribution Licence. Use, distribution and reproduction are unrestricted. Authors and original publication must be credited. 
of Eastern Asia (Goriup 1997). The species is classified as Vulnerable, primarily due to unregulated hunting and habitat loss (Birdlife International 2017). Globally, the current status of wild resident houbara populations is poorly known (BirdLife International 2016), with the latest studies on population trends conducted in the late 1990s (Seddon \& van Heezik 1996). More recent studies have examined nest site selection in Iran (Aghanajafizadeh et al. 2012) and reintroduced populations in Saudi Arabia (Islam et al. 2013) and the United Arab Emirates (UAE) (Azar et al. 2016), focusing on survival, densities or habitat selection, but none have examined population breeding parameters. Available data on the breeding parameters of wild populations are also limited, outdated, based on small samples or mainly concern the migrant populations (Table 1).

In the UAE, a resident breeding population formally existed as a part of the Arabian sub-region population (Goriup 1997). Since 2004, the National Avian Research Centre (NARC) has released captive-bred houbaras with the aim of restoring and maintaining a breeding population in a network of protected areas across the UAE (see www. houbarafund.org). By the end of 2016, 13504 houbara had been released in the UAE, of which 4474 were released in managed protected reserves of $\mathrm{Abu}$ Dhabi western area (see Supplement 1 at www.int-res.com/articles/suppl/n035 p059_supp.pdf). Ten years of individual monitoring in western Abu Dhabi reserves have highlighted the ability of captive-bred houbara to survive in the long term, with a mean $( \pm \mathrm{SD})$ annual survival of $0.48 \pm 0.12$ the first year and $0.54 \pm 0.08$ in the following years (Azar et al. 2016). However, the ability of these individuals to produce viable offspring remains to be assessed.

Here, we provide detailed information about breeding success in a reintroduced captive-bred population of resident houbara in western Abu Dhabi reserves. Specifically, we measured

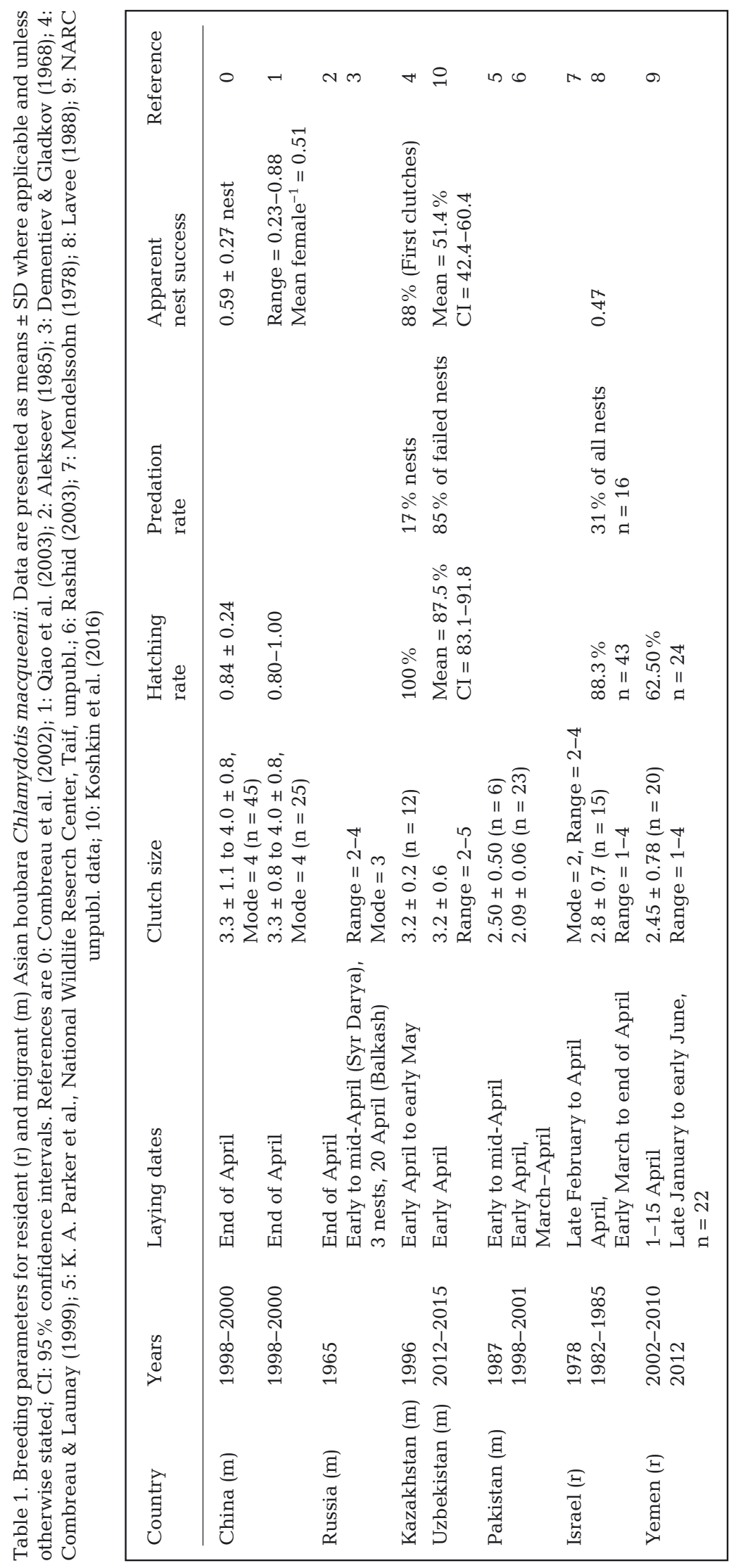


female breeding probability (the proportion of females that attempt to breed each year) and 5 nesting parameters (nest initiation date, clutch size, egg volume, daily nest survival rate and hatching rate), and we estimated chick survival as well as survival of juveniles $1 \mathrm{yr}$ after fledging. Bird breeding performance is driven by a set of individual characteristics (e.g. age and breeding experience) and environmental factors (Barbraud \& Weimerskirch 2005, Froy et al. 2013). In desert ecosystems, weather conditions (rainfall and temperature) are key factors affecting reproduction (e.g. timing of breeding, Dunn 2004, Small et al. 2007; female investment, Hargitai et al. 2005) directly, by influencing bird physiology, or indirectly, by regulating food availability (Golabek et al. 2012). Therefore, we exam-

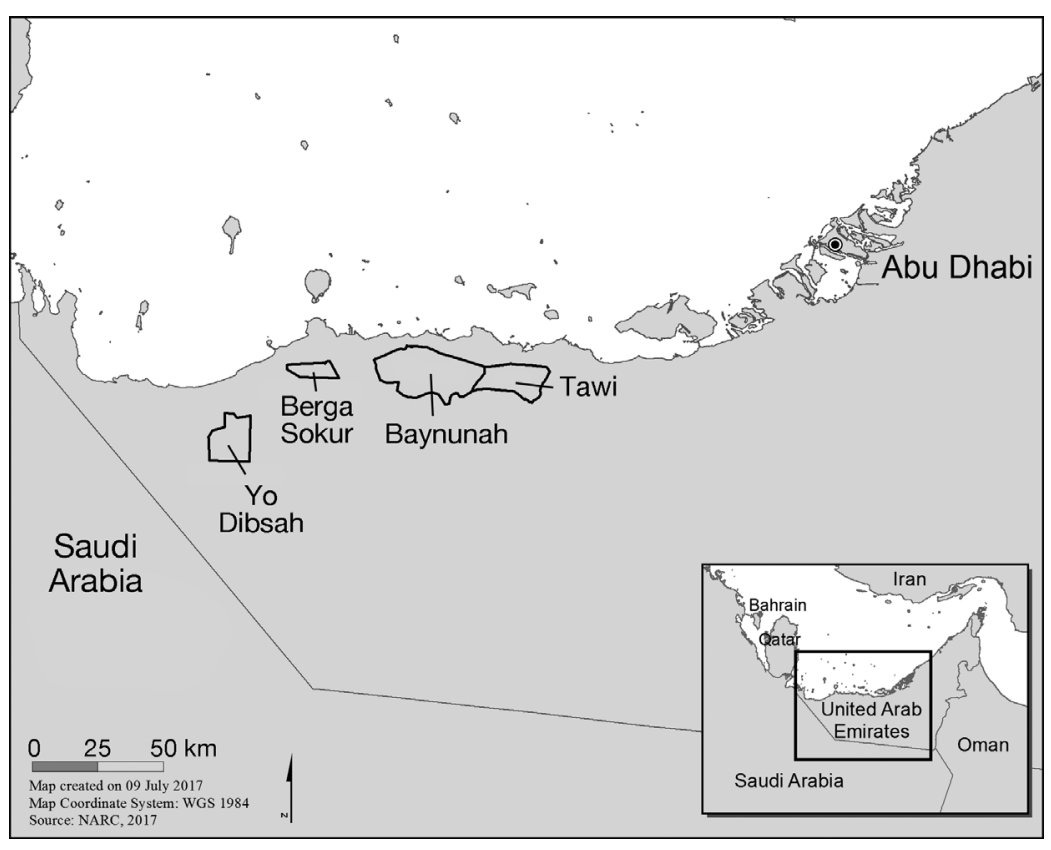

Fig. 1. The 4 main Asian houbara bustard Chlamydotis macqueenii reserves in western Abu Dhabi Emirate, United Arab Emirates ined the influence of female age, breeding experience, rainfall and temperature on nesting parameters. In addition, we modelled the influence of temperature, body condition and transmitter type on the weekly survival probability of juveniles. Finally, we estimated nest productivity, breeding success and population recruitment.

\section{MATERIALS AND METHODS}

\section{Study area}

The study was carried out from 2008 to 2015 in 4 reserves in western Abu Dhabi Emirate (Fig. 1): Baynunah Mignas $\left(531.13 \mathrm{~km}^{2}\right)$, Berga Sokur $\left(111.71 \mathrm{~km}^{2}\right)$, Tawi $\left(240.88 \mathrm{~km}^{2}\right)$ and Yo Dibsa $\left(215.68 \mathrm{~km}^{2}\right)$, all of which are managed specifically to increase Asian houbara Chlamydotis macqueenii survival (Azar et al. 2016). Management activities within the reserves include population reinforcement (see Supplement 1 at www.int-res.com/articles/suppl/n035p059_supp.pdf), fencing to exclude large grazing animals, regular patrolling to prevent poaching and providing supplementary food through the progressive establishment of plantations, representing $0.33 \%$ of the reserves in 2015. The dominant species planted are mustards Brassica spp., water spinach Ipomoea aquatica and moss rose Portulaca oleracea, which are maintained through artificial irrigation (Azar et al. 2016). The study area is characterised by a hot desert climate

corresponding to a Köppen classification of 'BWh' (Kottek et al. 2006), characterised by high humidity and low annual rainfall $(<40 \mathrm{~mm})$. Maximum summer temperature is approximately $47^{\circ} \mathrm{C}$ and minimum winter temperature is approximately $5^{\circ} \mathrm{C}$ (Bottomley 2008). Habitats in all 4 reserves are similar, each comprised of undulating sand dunes and gravel plains intermixed with flat salty areas (sabkhas) and sparse vegetation scattered between sand dunes. Vegetation is dominated by perennial shrubs, including hammada elegance Haloxylon salicornicum and Zygophyllum Zygophyllum spp.

\section{Nest search and female breeding probability}

Nests were located primarily by tracking 399 females equipped with transmitters, although some nests of unequipped females were occasionally located during fieldwork or by patrolling rangers. Tracked females were equipped with very high frequency (VHF) radio-transmitters (20 g backpack style; Merlin Systems) or platform transmitter terminal (PTT) satellite transmitters (30 g backpack; Microwave Telemetry), representing, 1.41 and $2.11 \%$, respectively, of the mean body weight of reintroduced adult females $(1419.37 \pm 148.71$ [SD] g, $\mathrm{n}=8$; NARC unpubl. data). Ground VHF radio-tracking was completed weekly throughout each breeding season, from the time the first displaying male was 
observed (generally in December) to fledging of chicks from the last nesting female, and every $2 \mathrm{wk}$ outside the breeding season. Coordinates of PTTtracked females were checked in a geographic information system (GIS) to identify any location clusters indicating potential nesting sites. These were then confirmed by weekly site visits. All captive-bred released houbara were marked with engraved coloured bands allowing the identification of nesting females not equipped with transmitters. Female breeding probability was estimated from tracked birds for 2 age groups: less than 1 yr old (newly released individuals) or older than 1 yr. Female breeding probability was estimated as the number of females that nested out of the total number of tracked females located weekly during a breeding season. Female breeding experience was categorised as whether a female had a previous nesting attempt (scored as 1) or not (scored as 0).

\section{Nest monitoring}

Nests were monitored by regular visits (weekly visits from date of nest discovery and daily visits in the $3 \mathrm{~d}$ prior to estimated hatching date) or via camera traps. Camera traps (Reconyx HC600 Hyperfire; RECONYX) were used from 2014 ( $\mathrm{n}=46$ nests from 40 females) for accurate determination of hatching rate, nest fate, hatching date and identification of nest predators. A camera trap was deployed within $1 \mathrm{wk}$ following the discovery of a nest, at a distance of $1 \mathrm{~m}$ from the nest. Nests monitored by camera traps were visited every $10 \mathrm{~d}$ to download pictures and replace batteries; the last visit was scheduled $4 \mathrm{~d}$ after the estimated hatching dates (see Supplement 2 at www.int-res.com/articles/suppl/n035p059 _supp.pdf).

\section{Nesting parameters}

Clutch size was defined as the maximum number of eggs observed in a nest during monitoring. Egg mass (measured with an electronic balance to the nearest $0.1 \mathrm{~g}$ ), and egg dimensions (measured using a dial or digital calliper to the nearest $0.1 \mathrm{~mm}$ ), were used to calculate egg volume in $\mathrm{mm}^{3}$ and estimate its development stage (see Supplement 2). Nest initiation date was defined as the median of estimated egg laying dates of each clutch. Egg laying date was calculated by subtracting the estimated development stage from its measurement date, or in case of known hatching date (e.g. using camera traps), by subtracting $23 \mathrm{~d}$ (mean incubation period; Combreau et al. 2002) from its observed hatching date. Hatching rate was calculated, excluding predated and abandoned nests, as the number of hatched eggs divided by the clutch size.

\section{Offspring monitoring}

Houbara chicks fledge at an average age of $8 \mathrm{wk}$ after hatching (Combreau et al. 2002). Because tagging with transmitters would increase their mortality (Combreau et al. 2002), they were not monitored individually, and their survival was estimated from weekly monitoring of brooding VHF-tracked females in 2014. Juveniles were then trapped by hand before fledging (Hardouin et al. 2012) and fitted with GSMGPS backpack transmitters (30 g Microwave Telemetry, $\mathrm{n}=10$ ) or VHF backpack radio-transmitters (20 g Merlin Systems, n = 19), with transmitters representing $<10 \%$ of their body mass. Transmitters were attached to juveniles using Teflon harnesses incorporating elastic that could expand as the birds grew (Combreau et al. 2011). VHF-equipped juveniles were monitored weekly from the ground and GSM-GPS transmitters were set to record 1 location every 2 min and to send locations daily.

\section{Weather conditions affecting nest parameters}

Houbara females lay eggs on average $2 \mathrm{wk}$ after insemination (Saint Jalme et al. 1994). Therefore, to study how weather conditions influence the timing of nest initiation and breeding parameters, total rainfall and mean maximum temperature $4 \mathrm{wk}$ prior to nest initiation date were used. To analyse effects of temperature during incubation on hatching rate, mean maximum temperature between nest initiation dates and nest hatching or abandonment dates were used. Total rainfall during the nesting period (the period between the first and last nest found each year) was used to study the influence of weather on the length of the breeding season. Weather data were obtained from the Global Land Data Assimilation System in 3-hour increments (Rodell \& Beaudoing 2016).

\section{Statistical analysis}

Generalised linear mixed models (GLMMs), conducted with the 'lme4' package (Bates et al. 2012) in 
R v.2.15.1 (R Development Core Team 2015) were used to model the influence of variables on breeding parameters. The influence of temperature (in quadratic terms) and rainfall on nest initiation date was modelled using binomial error with year as a random effect. The response variable was coded as nest (1)/no nest (0) for all dates between the minimum and maximum nest laying dates of all years. Time was included in the model to account for temporal autocorrelation (Zuur et al. 2009). Similarly, the influence of female age, temperature, rainfall and nest initiation date on egg volume was modelled using Gaussian error, with year and female identity as random effects. The influence of female age, nest initiation date, temperature and rainfall on clutch size was fitted with Poisson error, with female identity and year fitted as random factors. The influence of clutch size, female age and nest initiation date on hatching rate was modelled with a Gaussian error distribution, with hatching rate arcsine transformed prior to analysis (Noriyuki et al. 2012). Using the 'dredge' function in the 'MuMIn' package of R (Barton 2014), we generated subsets of models from global models. Pearson's correlation coefficient was used to measure the relationship between total rainfall during a breeding season and the length of the breeding season.

The influence of female age, nest initiation date, nest age at discovery and females' breeding experience on daily nest survival rates was modelled using a maximum likelihood approach implemented in the program MARK (White \& Burnham 1999) and run through the RMark package (Laake 2013). Nest survival (i.e. probability of a nest surviving from initiation to hatching of at least 1 egg) was calculated by raising the estimated daily nest survival rate to the power of the length of the incubation period (23 d).

Chick survival before fledging was defined as the ratio of the number of chicks seen with a tracked female 6 wk after hatching relative to the initial number of hatchlings for that female. After fledging, survival of juveniles was modelled using RMark (White \& Burnham 1999) to write Burnham joint live-dead models (Burnham 1993) into MARK (White \& Burnham 1999). Encounter histories were constructed into weekly occasions for $1 \mathrm{yr}$ of monitoring, and grouped into tri-monthly time periods. To reduce the number of models, we first selected the best time-varying model for survival and recapture probabilities. The influence of transmitter type, body condition (residuals of mass to tarsus length; Azar et al. 2016), ratio of transmitter mass to body mass and average weekly temperature were tested on the selected time model. We performed goodness-of-fit (GOF) tests for a single state model by using the program U-CARE (Choquet et al. 2009), as no specific test is available to assess GOF of the general model when combining live telemetry locations and dead recoveries (Duriez et al. 2009). Yearly survival rate was calculated using the delta method in the R package 'msm' (Jackson 2011).

Akaike's information criterion corrected for small sample sizes $\left(\mathrm{QAIC}_{\mathrm{c}}\right)$ was used to rank both GLMM and survival models, and $\triangle$ QAIC $_{\mathrm{c}}$ and Akaike weights $(w)$ were used to assess model likelihood and uncertainty (Burnham \& Anderson 2004). Model averaging was used to calculate average parameter estimates based on all models in which the parameter appeared, and the relative importance of each variable (RVI) in the top models $\left(\Delta\right.$ QAIC $\left._{c}<2\right)$ was calculated by summing the weights of all models containing that variable. Model-averaged parameters were considered strongly supported when their $95 \%$ unconditional confidence intervals did not span zero.

Nest productivity (average number of hatchlings per nest) was estimated as the product of nest survival $\times$ hatching rate $\times$ clutch size. Breeding success (average number of juveniles successfully raised to fledging by a nesting female) was estimated as the product of nest productivity $\times$ chick survival. Population recruitment (number of individuals added to the population after $1 \mathrm{yr}$ per female) was estimated as the product of female breeding probability $\times$ breeding success $\times$ juvenile survival.

\section{RESULTS}

Between 2008 and 2015, a total of 84 nests from captive-bred released females were found in the western reserves of Abu Dhabi (out of 110 nests found in the UAE as a whole). The number of nests found during 8 successive years was highly variable (mean $\pm \mathrm{SD}=10.50 \pm 17.71$ ), with the highest number of nests (58\%) found in 2014 (Fig. 2). Age of nesting females ranged from 10.82 mo to $7.71 \mathrm{yr}$ (mean $\pm \mathrm{SD}$ $=3.43 \pm 1.58 \mathrm{yr}, \mathrm{n}=70$ ). Female breeding probability was on average $0.14 \pm 0.31 \pm \mathrm{SD}(\mathrm{n}=8 \mathrm{yr}) ; 0.01 \pm 0.03$ for females $<1 \mathrm{yr}$ old and $0.23 \pm 0.38$ for females older than 1 yr. Median nest initiation date was day-of-theyear 57 (25 February). Nest initiation date was positively influenced by progress of the breeding season, time (RVI $=1, \beta=0.001,95 \% \mathrm{CI}=0.0007-0.0014)$ and negatively with temperature ${ }^{2}$ (RVI $=1, \beta=-0.04$, $95 \% \mathrm{CI}=-0.05$ to -0.02 ; Table 2). Rain did not influence nest initiation date, with RVI $=35 \%$ and CI spanning zero. Increase in rainfall during the nesting period caused a statistically significant increase in 


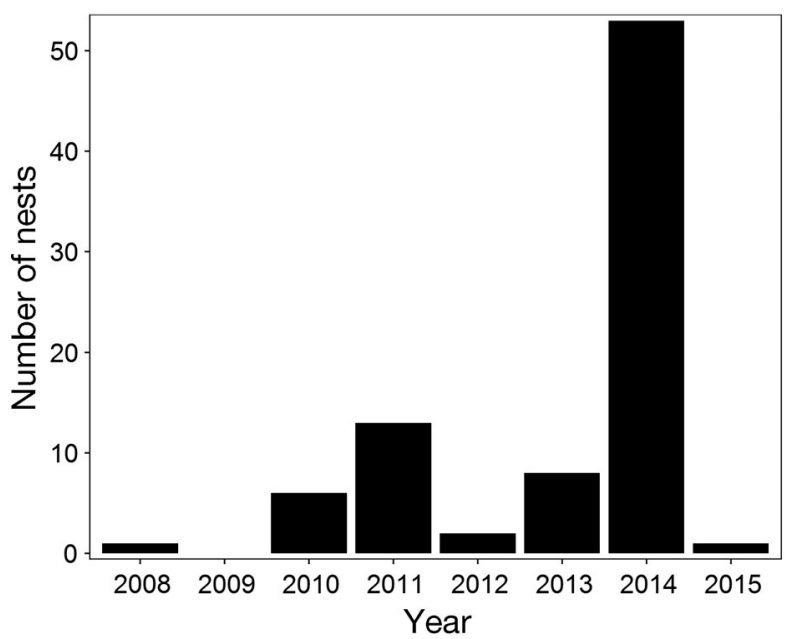

Fig. 2. Number of captive-bred Asian houbara bustard Chlamydotis macqueenii nests found each year in western Abu Dhabi Reserves

the length of the breeding season $(r=0.89, n=5, p=$ 0.04). A total of 209 eggs were laid, with a mean \pm SD clutch size of $2.49 \pm 0.72$ eggs ( $n=84$ nests). None of the tested parameters had an influence on clutch size; all displayed an RVI of $<20 \%$ and their CI spanned zero (Table 2). Mean \pm SD hatching rate was $0.79 \pm$ 0.25 ( $\mathrm{n}=51$ ) and was not influenced by any of the tested variables (Table 2). All tested variables had an RVI of $<33 \%$ and their CI spanned zero. Mean \pm SD egg volume was $46.65 \pm 22.86 \mathrm{~mm}^{3}$ ( $\mathrm{n}=27$ eggs) and was positively influenced by female age (RVI $=1, \beta=$ $0.01,95 \%$ CI = 0.001-0.02; Table 2).

\section{Nest survival}

Nest survival analysis was performed on nests monitored in 2014 only, when the majority of nests were found (Fig. 2), and monitored using camera traps. Nest survival was influenced by nest initiation date (Table 3); nests initiated later in a breeding season had lower daily nest survival rates $(\mathrm{RVI}=78 \%, \beta=-0.03$, $95 \%$ CI $=-0.06$ to -0.002 ; Fig. 3 ). Average daily nest survival for nests found in 2014 was $0.972 \pm 0.031 \mathrm{SE}$; therefore, average nest survival for the $23 \mathrm{~d}$ of incubation was 0.52 . Nest failure was caused mainly by egg predation $(66.67 \%) ; 60 \%$ of nest depredations occurred after the median nest initiation date (1 March), followed by nest abandonment (33.33\%); $63 \%$
Table 2. Models of nest initiation date, clutch size, hatching rate, and egg volume of captive-bred Asian houbara bustard Chlamydotis macqueenii in western Abu Dhabi reserves, United Arab Emirates, 2008-2015. Only a limited number of relevant models are presented here for clarity. $K$ : number of parameters; $\mathrm{AIC}_{\mathrm{c}}$ : Akaike's information criterion adjusted for small sample sizes; $\Delta \mathrm{AIC}_{\mathrm{c}}$ : change in $\mathrm{AIC}_{\mathrm{c} i} w_{i}$ : Akaike weight

\begin{tabular}{|c|c|c|c|c|}
\hline Model & $K$ & $\mathrm{AIC}_{\mathrm{C}}$ & $\Delta \mathrm{AIC}_{\mathrm{c}}$ & $w_{i}$ \\
\hline \multicolumn{5}{|l|}{ Egg volume } \\
\hline Female age + rainfall & 5 & 54.80 & 0.00 & 0.55 \\
\hline Female age & 4 & 56.14 & 1.34 & 0.28 \\
\hline $\begin{array}{l}\text { Clutch size + female age } \\
\text { + rainfall }\end{array}$ & 6 & 58.84 & 4.04 & 0.07 \\
\hline Clutch size + female age & 5 & 59.72 & 4.92 & 0.05 \\
\hline \multicolumn{5}{|l|}{ Hatching rate } \\
\hline $\begin{array}{l}\text { (Null) } \\
\text { Clutch size }\end{array}$ & $\begin{array}{l}3 \\
4\end{array}$ & $\begin{array}{l}112.27 \\
101.87\end{array}$ & $\begin{array}{c}0 \\
10.40\end{array}$ & $\begin{array}{l}0.99 \\
0.01\end{array}$ \\
\hline Female age & 4 & 94.76 & 17.51 & 0 \\
\hline \multicolumn{5}{|l|}{ Clutch size } \\
\hline Female age & 2 & 103.7 & 1.13 & 0.15 \\
\hline Temperature & 2 & 104.23 & 1.66 & 0.11 \\
\hline Nest initiation date & 2 & 104.42 & 1.85 & 0.10 \\
\hline Rainfall & 2 & 104.48 & 1.91 & 0.09 \\
\hline \multicolumn{5}{|l|}{ Nest initiation date } \\
\hline Temperature $^{2}+$ time & 3 & 279.39 & 0 & 0.65 \\
\hline Temperature $^{2}+$ time + rain & 4 & 280.64 & 1.25 & 0.35 \\
\hline Temperature $^{2}+$ rainfall & 3 & 312.89 & 33.50 & 0 \\
\hline Temperature $^{2}$ & 5 & 297.19 & 4.64 & 0 \\
\hline
\end{tabular}

of abandoned nests occurred after the median nest initiation date. Photos from camera traps (46 nests) revealed that red fox Vulpes vulpes was the principal nest predator ( $88 \%$ of predated nests). Age of a nesting female had the second highest RVI (25\%) but was not statistically significant as its confidence intervals spanned zero $(\beta=-0.01,95 \% \mathrm{CI}=$ $-0.05-0.03)$.

Table 3. Candidate models used to analyse nest survival $(\varphi)$ of captive-bred Asian houbara bustard Chlamydotis macqueenii in western Abu Dhabi, United Arab Emirates, in 2014. Only a limited number of relevant models are presented here for clarity. K: number of parameters; $\mathrm{AIC}_{\mathrm{c}}$ : Akaike's information criterion adjusted for small sample sizes; $\Delta \mathrm{AIC}_{\mathrm{c}}$ : change in $\mathrm{AIC}_{\mathrm{c} i} w_{i}$ : Akaike weight; Dev: deviance

\begin{tabular}{|lccccc|}
\hline Model & $K$ & $\mathrm{AIC}_{\mathrm{c}}$ & $\Delta \mathrm{AIC}_{\mathrm{c}}$ & $w_{i}$ & $\mathrm{Dev}$ \\
\hline$\varphi$ (Nest initiation date) & 2 & 94.70 & 0.00 & 0.50 & 90.67 \\
$\varphi$ (Nest initiation date + female age) & 3 & 96.44 & 1.73 & 0.21 & 90.38 \\
$\varphi(\sim 1)$ & 1 & 97.15 & 2.45 & 0.15 & 95.14 \\
$\varphi$ (Nest initiation date + female previous & & & & & \\
$\quad$ breeding attempt) & 4 & 98.59 & 3.88 & 0.07 & 90.49 \\
$\varphi$ (Female age) & 2 & 99.16 & 4.46 & 0.05 & 95.13 \\
$\varphi$ (Female previous breeding attempt) & 3 & 101.18 & 6.48 & 0.02 & 95.12 \\
\hline
\end{tabular}




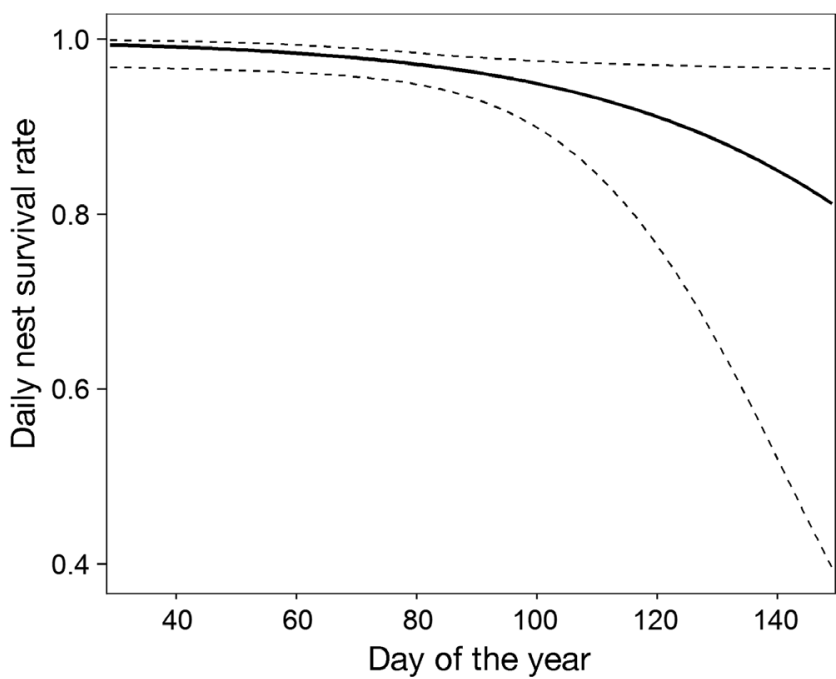

Fig. 3. Daily nest survival rate of captive-bred Asian houbara bustard Chlamydotis macqueenii during 2014. Dashed lines represent $95 \%$ CI

\section{Offspring survival}

Chick survival to the age of 6 wk was $0.50 \pm 0.39$ $\mathrm{SD}$. The GOF test for juvenile survival $1 \mathrm{yr}$ after fledging was statistically significant for live recaptures $\left(\chi_{53}^{2}=55.16, p<0.01\right)$, revealing overdispersion, while it was not statistically significant for dead recoveries $\left(\chi_{5}^{2}=0.94, p=0.96\right)$. An overdispersion was estimated $(\hat{c}=1.04)$, and was used to correct any potential violation of independence between individuals (Cooch \& White 2001). The best time-varying model showed that survival varied with time (measured every 3 months) and constant recapture probability $\left(\Delta \mathrm{QAIC} \mathrm{c}_{\mathrm{c}}=5.52\right)$, therefore covariates were tested assuming this model. Averaged models showed no support for any of the tested variables on

Table 4. Candidate models used to analyse variation of weekly survival of juvenile Asian houbara bustard Chlamydotis macqueenii hatched in western Abu Dhabi reserves, United Arab Emirates, in 2014, showing only survival $(\varphi)$ and detection $(p)$ probabilities. Only a limited number of relevant models are presented here for clarity. $K$ : number of parameters; $\mathrm{AIC}_{\mathrm{c}}$ : Akaike's information criterion adjusted for small sample sizes; $\Delta \mathrm{AIC}_{\mathrm{c}}$ : change in $\mathrm{AIC}_{\mathrm{c} i} w_{i}$ : Akaike weight; Dev: deviance

\begin{tabular}{|lcccccc|}
\hline Model & & $K$ & $\mathrm{AIC}_{\mathrm{c}}$ & $\Delta \mathrm{AIC}_{\mathrm{c}}$ & $w_{i}$ & $\mathrm{Dev}$ \\
\hline$\varphi(\sim$ Time) & $p$ (model) & 8 & 824.05 & 0 & 0.31 & 746.49 \\
$\varphi$ (Time + body condition) & $p$ (model) & 9 & 825.53 & 1.48 & 0.15 & 807.31 \\
$\varphi$ (Time + trans to body mass) & $p$ (model) & 9 & 825.99 & 1.94 & 0.12 & 807.77 \\
$\varphi$ (Time + temperature) & $p$ (model) & 9 & 826.10 & 2.04 & 0.11 & 746.49 \\
$\varphi$ (Time + model) & $p$ (model) & 9 & 826.11 & 2.04 & 0.11 & 746.50 \\
$\varphi$ (Time+ body condition & $p$ (model) & 10 & 827.54 & 3.5 & 0.05 & 807.27 \\
$\quad$ + trans to body mass) & & & & & & \\
\hline
\end{tabular}

survival (RVI $<25 \%$ for all the tested variables; Table 4). The mean tri-monthly survival rate was 0.97 $\pm 0.01 \mathrm{SE}$, and the $1 \mathrm{yr}$ survival rate (52 wk) was 0.64 \pm 0.02 SE. Nest productivity was 1.02 hatchlings nest $^{-1}$ and breeding success was 0.51 fledging chicks per breeding female. The population recruitment rate was estimated as 0.05 ind. female ${ }^{-1}$ in the population; 0.006 for females $<1 \mathrm{yr}$ and 0.09 for females $>1$ yr old.

\section{DISCUSSION}

Long-term individual monitoring of reintroduced resident houbara Chlamydotis macqueenii in western Abu Dhabi reserves provides evidence that captive-bred individuals are able to survive in the long term (Azar et al. 2016). However, population recruitment was generally limited, as a result of low and stochastic female breeding probability.

Breeding parameters of reintroduced houbara in UAE were globally low but similar to the very few reported in other studies of wild resident houbara populations (Table 1). Breeding parameters of resident houbara populations are lower than those of migrant houbaras (Table 1). For example, nest productivity of resident houbara in the UAE and in the Negev Desert were equivalent (1.02 and 0.95 hatchlings nest ${ }^{-1}$ respectively), but were lower than for migrant houbara in China (1.8 hatchlings nest ${ }^{-1}$ ), resulting mainly from smaller clutch size in resident houbara populations (Table 1). Clutch sizes of reintroduced resident houbara in the UAE were similar to those reported from wild populations in areas characterised by hot desert climates (Kottek et al. 2006), i.e. Pakistan, Yemen and the Negev Desert (Table 1). Smaller clutches in a desert ecosystem might be a consequence of lower food availability, either because larger broods will require more food resources, or because smaller clutches allow for rapid replacement of failed nests (Zanette et al. 2006). Conversely, the larger clutches observed in migrant houbara populations might be a product of a time-constrained breeding season, where increasing clutch size can maximise productivity (Combreau et al. 2002). Animal productivity in desert ecosystems, while generally low, is known to be highly variable between years due to the high interannual variability of rainfall (Noy- 
Meir 1973). This is reflected in our results, with female breeding probability and the number of nests found being low and highly variable between years. Such stochasticity in breeding effort is a common pattern in desert birds, reflecting their plasticity and ability to increase their breeding effort when environmental conditions are favourable (Costa 1995). Furthermore, it is known that reproductive performance improves with age in African houbara bustards C. undulata, which reach their peak reproductive performance at the age of 4 yr (Preston et al. 2015) mainly by increasing courtship display rates and egg production (Chantepie et al. 2015). The reintroduced houbara population in western Abu Dhabi is mainly composed of young individuals due to the increasing number of young birds $(<12 \mathrm{mo})$ released each year (see Supplement 1) in conjunction with low survival rates (Azar et al. 2016), which contributes to the low breeding performance of the population. In our study, females older than 1 yr had a higher breeding probability and laid larger eggs. In general, larger egg size results in offspring with larger mass after hatching (Amundsen 1995, Styrsky et al. 1999), which may have a positive effect on their survival (Blomqvist et al. 1997, Risch \& Rohwer 2000). However, female age had no effect on clutch size, likely due to a strong influence of harsh environmental conditions on female investment.

Our study population was bred in captivity. The demography of translocated populations, especially those based on captive-bred animals, is known to suffer a substantial release cost, influencing their survival, movements and breeding probability (Sarrazin et al. 1996, Bertolero \& Oro 2009, Le Gouar et al. 2012). This cost might be explained by genetic processes, such as outbreeding depression, inbreeding, drift loads and adaptation to captivity (Frankham 2008). However, these processes are unlikely to explain the observed low breeding success of reintroduced females in the UAE, because the captive breeding programme in the UAE follows a strict genetic programme based on maximising genetic diversity and the representation of founders (Lesobre et al. 2010), and breeding parameters were within the range of known parameters obtained from resident wild populations (Table 1). The observed low breeding probability might therefore rather be linked to non-genetic factors, such as bird condition (Champagnon et al. 2012), behaviour (Tavecchia et al. 2009) or external conditions (weather and management practices; Azar et al. 2016). In the absence of data on breeding probability from wild resident houbara in arid environments, the relative influence of these factors cannot be assessed, and further investigations are required.
Weather conditions are known to influence the onset of the breeding season (Wingfield 1984), and in many desert species, rainfall and temperature patterns have been the focus of interest regarding environmental influence on breeding ecology (Zann et al. 1995). Our results showed that rainfall during a breeding season increased its length, potentially as a direct factor inducing a physiological adjustment in females (Dawson 2008), or indirectly through extending favourable environmental conditions that may stimulate more females to breed or re-clutch after a nesting failure. However, rainfall did not stimulate the onset of the houbara breeding season, a result that is in concordance with previously reported findings on captive houbara breeding in outdoor enclosures (Van Heezik et al. 2002, Maloney 2003) and other desert species (Zann et al. 1995, Schaub et al. 2009). Rather, the onset of breeding is generally controlled by an increase in temperature (Wingfield 1984), or by an increase in photoperiod (Lambrechts et al. 1997), which is also associated with progress into the breeding season, these 2 factors acting simultaneously with the seasonal shift from winter to spring. The importance of temperature has been reported for species inhabiting temperate regions (Lack 1950, Slagsvold 1976, Dunn 2004); however, it remains poorly documented in desert species (Barrientos et al. 2007) where early winter temperature is not as cold. Interestingly, in our analysis the increase in temperature was associated with the onset and termination of the breeding season of houbara. However, such a relationship requires further study which should take into account the possible confounding effects of photoperiod.

Nest predation is the main cause of nest failure in many bird species (Muchai \& du Plessis 2005). The percentage of predated nests in the UAE $(30 \%)$ is within the range of reported predation rates for the species (Table 1). Nest survival decreased throughout the breeding season primarily due to increased predation rates, which may result from an increase in the nutritional demand of predators to feed their offspring (Wilson et al. 2007). In addition, most nest abandonment occurred late in the season when heat stress increased with the beginning of summer (Wingfield 1984). A similar time-dependent effect has been reported by Koshkin et al. (2016) in Uzbekistan and by Bacon et al. (2017) in the closely related African houbara.

Surprisingly, nest abandonment was the secondary cause of nest failure, despite apparently low anthropogenic disturbances like herding (Chamberlain \& Crick Humphrey 2003), land use or tourism (Beale \& 
Monaghan 2004). To our knowledge, nest abandonment has not been previously reported as a main cause of nest failure in resident or migratory houbara. However, other potential sources of disturbance require further investigation, such as the maintenance of plantations by workers or research activities. In addition, other causes of nest desertion need to be investigated; for example, houbara densities and sex ratios in the vicinity of plantations which may favour male harassment of nesting females (Rowe et al. 1994), or severe weather conditions (Sherley et al. 2012).

Survival of wild-born juveniles was constant during the first year and was not influenced by any of the tested variables. On average, wild-born juvenile houbara possessed a yearly survival probability higher than that of captive-bred released juveniles $(0.48 \pm 0.12 \mathrm{SD})$ in the first year after release (Azar et al. 2016). Higher survival rates in wild-born houbara might result from parental learning (Nicoll et al. 2004), improved foraging abilities (spatial directions, feeding site locations and prey selection; Arnold et al. 2007), effectively coping with the harsh climate, predation avoidance, or the ability to socialize with adults (Brown et al. 2006).

Our results demonstrate that female captive-bred released houbara in the UAE are able to breed; however, population recruitment remains low, probably due to harsh weather conditions in the desert ecosystem. Desert bird populations are generally small with low productivity and their viability relies mostly on adult survival. Due to their low demographic resilience, perturbations such as rapid habitat loss and over-hunting may quickly lead to their extirpation. Reserves in the UAE were created to protect houbara from such anthropogenic disturbances, but their management practices might also influence their demographic parameters. Therefore, a detailed understanding of how management practices may influence (positively or negatively) breeding success is crucial. For example, female breeding probability and nest productivity can be affected by changes in population density (Carrete et al. 2006), sex-ratio and population structure (Fry et al. 1987) caused by population reinforcement, which has already been shown to affect adult houbara survival (Azar et al. 2016).Temporal changes in the quantity and quality of supplementary food resources provided to houbara through the plantations, along with their spatial distribution within reserves may also influence population recruitment (Arcese \& Smith 1988, Verhulst 1994, Davies \& Deviche 2014). Agricultural practices (the use of fertilisers or pesticides) can also have an impact on breeding (Fluetsch \& Sparling 1994). In addition, nesting success can be influenced by the availability of suitable nesting sites within fenced areas (Kolbe \& Janzen 2002). Therefore, further studies aimed at disentangling the effects of weather conditions and reserve management practices are required.

Acknowledgements. This study was funded by the National Avian Research Centre, a project supported by the International Fund for Houbara Conservation (IFHC). We are grateful to H. H. Sheikh Mohammed bin Zayed Al Nahyan, Crown Prince of Abu Dhabi and Chairman of the IFHC, and H. E. Mohammed Al Bowardi, Deputy Chairman of IFHC, for their support. This study was completed under the guidance of Reneco International Wildlife Consultants, LLC, a consulting company managing NARC. We are thankful to Frédéric Lacroix, managing director, for his supervision. We sincerely thank all NARC employees involved in data collection. Bird monitoring within UAE Houbara Reserves was made possible with the support of the Abu Dhabi Environment Agency and the cooperation of rangers. We thank Dr. Tom Martin for his helpful comments and improvement of the English text.

\section{LITERATURE CITED}

Aghanajafizadeh S, Hemami MR, Heydari F (2012) Nest-site selection by the Asian houbara bustard, Chlamydotis macqueenii, in the steppe of Harat, Iran (Aves: Otidae). Zool Middle East 57:11-18

Alekseev AF (1985) The houbara bustard in the north-west Kyzylkum (USSR). Bustard Stud 3:87-92

Amundsen T (1995) Egg size and early nestling growth in the snow petrel. Condor 97:345-351

Arcese P, Smith JN (1988) Effects of population density and supplemental food on reproduction in song sparrows. J Anim Ecol 57:119-136

Arnold KE, Ramsay SL, Donaldson C, Adam A (2007) Parental prey selection affects risk-taking behaviour and spatial learning in avian offspring. Proc R Soc B 274: 2563-2569

* Azar JF, Rautureau P, Lawrence M, Calabuig G, Hingrat Y (2016) Survival of reintroduced Asian houbara in United Arab Emirates' reserves. J Wildl Manag 80:1031-1039

* Bacon L, Hingrat Y, Jiguet F, Monnet AC, Sarrazin F, Robert A (2017) Habitat suitability and demography, a timedependent relationship. Ecol Evol 7:2214-2222

*Barbraud C, Weimerskirch H (2005) Environmental conditions and breeding experience affect costs or reproduction in blue petrels. Ecology 86:682-692

Barrientos R, Barbosa A, Valera F, Moreno E (2007) Temperature but not rainfall influences timing of breeding in a desert bird, the trumpeter finch (Bucanetes githagineus). J Ornithol 148:411-416

* Barton K (2014) MuMIn: multi-model inference. R package version 1.10.5. http://CRAN.R-project.org/package=Mu MIn (accessed 15 April 2017)

Bates D, Maechler M, Bolker B (2012) lme4: linear mixedeffects models using $\mathrm{S} 4$ classes. $\mathrm{R}$ package version 0.999999-0

Beale CM, Monaghan P (2004) Human disturbance: People as predation-free predators? J Appl Ecol 41:335-343 
Bertolero A, Oro D (2009) Conservation diagnosis of reintroducing Mediterranean pond turtles: What is wrong? Anim Conserv 12:581-591

BirdLife International (2016) Species factsheet: Chlamydotis macqueenii. http://datazone.birdlife.org/species/factsheet/asian-houbara-chlamydotis-macqueenii (accessed 17 July 2016)

BirdLife International (2017) Chlamydotis macqueenii (amended version of assessment). The IUCN Red List of Threatened Species 2017: e.T22733562A118585210. http:// dx.doi.org/10.2305/IUCN.UK.2017-3.RLTS.T22733562A 118585210.en (accessed 4 July 2016)

Blomqvist D, Johansson OC, Gottmark F (1997) Parental quality and egg size affect chick survival in a precocial bird, the lapwing Vanellus vanellus. Oecologia 110:18-24

Bottomley N (2008) Recent climate of Abu Dhabi. In: Perry RJ (ed) Terrestrial environment of Abu Dhabi Emirate. Environmental Agency, Abu Dhabi

Brown JL, Collopy MW, Gott EJ, Juergens PW, Montoya AB, Hunt WG (2006) Wild-reared aplomado falcons survive and recruit at higher rates than hacked falcons in a common environment. Biol Conserv 131:453-458

Burnham KP (1993) A theory for combined analysis of ring recovery and recapture data. In: Lebreton JD, North PM (eds) Marked individuals in the study of bird population. Birkhäuser-Verlag, Basel, p 199-213

* Burnham KP, Anderson DR (2004) Multimodel inference understanding AIC and BIC in model selection. Sociol Methods Res 33:261-304

Carrete M, Donázar JA, Margalida A (2006) Density-dependent productivity depression in Pyrenean bearded vultures: implications for conservation. Ecol Appl 16: 1674-1682

Chamberlain DE, Crick Humphrey QP (2003) Temporal and spatial associations in aspects of reproductive performance of lapwings Vanellus vanellus in the United Kingdom, 1962-99. Ardea 91:183-196

Champagnon J, Guillemain M, Elmberg J, Massez G, Cavallo F, Gauthier-Clerc M (2012) Low survival after release into the wild: assessing 'the burden of captivity' on Mallard physiology and behaviour. Eur J Wildl Res 58: 255-267

Chantepie S, Robert A, Sorci G, Hingrat Y and others (2015) Quantitative genetics of the aging of reproductive traits in the houbara bustard. PLOS ONE 10:e0133140

* Choquet R, Lebreton JD, Gimenez O, Reboulet AM, Pradel R (2009) U_CARE: Utilities for performing goodness of fit tests and manipulating CApture-REcapture data. Ecography 32:1071-1074

Combreau O, Launay F (1999) An estimation of the nesting success in a houbara bustard Chlamydotis undulata macqueenii population in Kazakhstan. Sandgrouse 21: $171-175$

Combreau O, Qiao J, Lawrence M, Gao X, Yao J, Yang W, Launay F (2002) Breeding success in a houbara bustard Chlamydotis [undulata] macqueenii population on the eastern fringe of the Jungar Basin, People's Republic of China. Ibis 144:E45-E56

Combreau O, Riou S, Judas J, Lawrence M, Launay F (2011) Migratory pathways and connectivity in Asian houbara bustards: evidence from 15 years of satellite tracking. PLOS ONE 6:e20570

Cooch E, White GC (2001) Program MARK: analysis of data from marked individuals, a gentle introduction. www. phidot.org/software/mark/docs/book
Costa G (1995) Behavioural adaptations of desert animals. Springer-Verlag, Berlin

* Davies S, Deviche P (2014) At the crossroads of physiology and ecology: food supply and the timing of avian reproduction. Horm Behav 66:41-55

Dawson A (2008) Control of the annual cycle in birds: endocrine constraints and plasticity in response to ecological variability. Philos Trans R Soc Lond B 363:1621-1633

Dementiev GP, Gladkov NA (1968) Ptitsy Sovetskogo Soyuza [Birds of Soviet Union], Vol 2. Israel Program for Scientific Translations, Jerusalem

* Dunn P (2004) Breeding dates and reproductive performance. Adv Ecol Res 35:69-87

Duriez O, Sæther SA, Ens BJ, Choquet R, Pradel R, Lambeck $\mathrm{RH}$, Klaassen M (2009) Estimating survival and movements using both live and dead recoveries: a case study of oystercatchers confronted with habitat change. J Appl Ecol 46:144-153

Fluetsch KM, Sparling DW (1994) Avian nesting success and diversity in conventionally and organically managed apple orchards. Environ Toxicol Chem 13:1651-1659

* Frankham R (2008) Genetic adaptation to captivity in species conservation programs. Mol Ecol 17:325-333

*Froy H, Phillips RA, Wood AG, Nussey DH, Lewis S (2013) Age-related variation in reproductive traits in the wandering albatross: evidence for terminal improvement following senescence. Ecol Lett 16:642-649

Fry DM, Toone CK, Speich SM (1987) Sex ratio skew and breeding patterns of gulls: demographic and toxicological considerations. Stud Avian Biol 10:26-43

*Golabek KA, Ridley AR, Radford AN (2012) Food availability affects strength of seasonal territorial behaviour in a cooperatively breeding bird. Anim Behav 83:613-619

Goriup PD (1997) The world status of the houbara bustard Chlamydotis undulata. Bird Conserv Int 7:373-397

*Hardouin L, Nevoux M, Robert A, Gimenez O, Lacroix F, Hingrat Y (2012) Determinants and costs of natal dispersal in a lekking species. Oikos 121:804-812

*Hargitai R, Török J, Tóth L, Hegyi G and others (2005) Effects of environmental conditions and parental quality on inter- and intraclutch egg-size variation in the collared flycatcher (Ficedula albicollis). Auk 122:509-522

Hoyo J, Elliott A, Sargatal J (1996) Handbook of the birds of the world, Vol 3. Hoatzin to auks. Lynx Edicions, Barcelona

ㄴ. Islam MZ, Singh A, Basheer MP, Judas J, Boug A (2013) Differences in space use and habitat selection between captive-bred and wild-born houbara bustards in Saudi Arabia: results from a long-term reintroduction program. J Zool (Lond) 289:251-261

*IUCN (2013) Guidelines for reintroductions and other conservation translocations, version 1.0. IUCN Species Survival Commission Reintroduction Specialist Group, Gland. https://portals.iucn.org/library/efiles/documents/ 2013-009.pdf (accessed 17 July 2016)

Jackson CH (2011) Multi-state models for panel data: the msm package for R. J Stat Softw 38:1-29

Kolbe JJ, Janzen FJ (2002) Impact of nest-site selection on nest success and nest temperature in natural and disturbed habitats. Ecology 83:269-281

Koshkin MA, Burnside RJ, Packman CE, Collar NJ, Dolman PM (2016) Effects of habitat and livestock on nest productivity of the Asian houbara Chlamydotis macqueenii in Bukhara Province, Uzbekistan. Eur J Wildl Res 62: $447-459$ 
Kottek M, Grieser J, Beck C, Rudolf B, Rubel F (2006) World map of the Köppen-Geiger climate classification updated. Meteorol Z (Berl) 15:259-263

Laake JL (2013) RMark: an R interface for analysis of capture-recapture data with MARK. AFSC Processed Report 2013-01. Alaska Fisheries Science Center, NOAA, National Marine Fisheries Service, Seattle, WA

Lack D (1950) The breeding seasons of European birds. Ibis 92:288-316

KLambrechts MM, Blondel J, Maistre M, Perret P (1997) A single response mechanism is responsible for evolutionary adaptive variation in a bird's laying date. Proc Natl Acad Sci USA 94:5153-5155

* Lavee D (1988) Why is the houbara Chlamydotis undulata macqueenii still an endangered species in Israel? Biol Conserv 45:47-54

Le Gouar P, Mihoub JB, Sarrazin F (2012) Dispersal and habitat selection: behavioural and spatial constraints for animal translocations. In: Ewen JG, Armstrong DP, Parker KA, Seddon P (eds) Reintroduction biology: integrating science and management. John Wiley \& Sons, Oxford, p 138-164

Lesobre L, Lacroix F, Caizergues A, Hingrat Y, Chalah T, Saint Jalme M (2010) Conservation genetics of houbara bustard (Chlamydotis undulata undulata): population structure and its implications for the reinforcement of wild populations. Conserv Genet 11:1489-1497

Maloney RF (2003) Survival, breeding and movements of reintroduced Asiatic houbara (Chlamydotis [undulata] macqueenii) in Mahazat As-Sayd reserve, Saudi Arabia. PhD thesis, University of New England, Biddeford, ME

Mendelssohn H (1978) Development of houbara (Chlamydotis undulata) populations in Israel and captive breeding. In: Coles CL, Collar NJ (eds) Symposium papers: the great bustard (Otis tarda), Sofia, Bulgaria, May 26 ${ }^{\text {th }}, 1978$ [and] the houbara bustard (Chlamydotis undulata), Athens, Greece, May $24^{\text {th }} 1979$. The Game Conservancy, Fordingbridge, p 75-89

Muchai M, du Plessis MA (2005) Nest predation of grassland bird species increases with parental activity at the nest. J Avian Biol 36:110-116

Nicoll MAC, Jones CG, Norris K (2004) Comparison of survival rates of captive-reared and wild-bred Mauritius kestrels (Falco punctatus) in a re-introduced population. Biol Conserv 118:539-548

Noriyuki S, Osawa N, Nishida T (2012) Asymmetric reproductive interference between specialist and generalist predatory ladybirds. J Anim Ecol 81:1077-1085

Noy-Meir I (1973) Desert ecosystems: environment and producers. Annu Rev Ecol Syst 4:25-51

Parker KA, Dickens MJ, Clarke RH, Lovegrove TG (2012) The theory and practice of catching, holding, moving and releasing animals. In: Ewen JG, Armstrong DP, Parker KA, Seddon P (eds) Reintroduction biology: integrating science and management. John Wiley \& Sons, Oxford, p 105-137

* Preston BT, Saint Jalme M, Hingrat Y, Lacroix F, Sorci G (2015) The sperm of aging male bustards retards their offspring's development. Nat Commun 6:6146

Qiao JF, Yang WK, Combreau O, Xingyi G (2003) Breeding success of houbara bustard (Chlamydotis undulata macqueenii) population in Mulei, Xinjiang. Dong Wu Xue Bao 49:310-315

R Development Core Team (2015) R: a language and environment for statistical computing. $\mathrm{R}$ Foundation for
Statistical Computing, Vienna

Rashid H (2003) Breeding biology of houbara bustard in Pakistan and Uzbekistan. PhD thesis, University of the Punjab, Lahore

Riou S, Combreau O (2014) Male territories and the lek-like mating system of MacQueen's bustard Chlamydotis macqueenii. J Ornithol 155:959-967

Risch TS, Rohwer FC (2000) Effects of parental quality and egg size on growth and survival of herring gull chicks. Can J Zool 78:967-973

Rodell M, Beaudoing HK (2016) NASA/GSFC/HSL (08.1), GLDAS Noah Land Surface Model L4 3 Hourly $0.25 \mathrm{x}$ 0.25 degree Subsetted, version 001. Goddard Earth Sciences Data and Information Services Center, Greenbelt, $\mathrm{MD}$

Rout TM, Hauser CE, Possingham HP (2009) Optimal adaptive management for the translocation of a threatened species. Ecol Appl 19:515-526

Rowe L, Arnqvist G, Sih A, Krupa JJ (1994) Sexual conflict and the evolutionary ecology of mating patterns: water striders as a model system. Trends Ecol Evol 9:289-293

Saint Jalme M, Gaucher P, Paillat P (1994) Artificial insemination in houbara bustards (Chlamydotis undulata): influence of the number of spermatozoa and insemination frequency on fertility and ability to hatch. J Reprod Fertil 100:93-103

* Sarrazin F, Bagnolip C, Pinna JL, Danchin E (1996) Breeding biology during establishment of a reintroduced griffon vulture Gyps fulvus population. Ibis 138:315-325

* Schaub M, Zink R, Beissmann H, Sarrazin F, Arlettaz R (2009) When to end releases in reintroduction programmes: demographic rates and population viability analysis of bearded vultures in the Alps. J Appl Ecol 46: 92-100

* Seddon PJ, van Heezik Y (1996) Seasonal changes in houbara bustard Chlamydotis undulata macqueenii numbers in Harrat al Harrah, Saudi Arabia: implications for managing a remnant population. Biol Conserv 75:139-146

Seddon P, Strauss WM, Innes I (2012) Animal translocations: What are they and why do we do them? In: Ewen JG, Armstrong DP, Parker KA, Seddon P (eds) Reintroduction biology: integrating science and management. John Wiley \& Sons, Oxford, p 1-32

* Sherley RB, Ludynia K, Underhill LG, Jones R, Kemper J (2012) Storms and heat limit the nest success of bank cormorants: implications of future climate change for a surface-nesting seabird in southern Africa. J Ornithol 153: 441-455

Slagsvold T (1976) Annual and geographical variation in the time of breeding of the great tit Parus major and the pied flycatcher Ficedula hypoleuca in relation to environmental phenology and spring temperature. Ornis Scand 7: 127-145

Small TW, Sharp PJ, Deviche P (2007) Environmental regulation of the reproductive system in a flexibly breeding Sonoran desert bird, the rufous-winged sparrow, Aimophila carpalis. Horm Behav 51:483-495

* Styrsky JD, Eckerle KP, Thompson CF (1999) Fitness-related consequences of egg mass in nestling house wrens. Proc R Soc B 266:1253-1258

Sutherland WJ (1996) From individual behaviour to population ecology. Oxford University Press, Oxford

Tavecchia G, Viedma C, Martínez-Abraín A, Bartolomé MA, Gómez JA, Oro D (2009) Maximizing re-introduction success: assessing the immediate cost of release in a 
threatened waterfowl. Biol Conserv 142:3005-3012

Van Heezik Y, Seddon PJ (1999) Seasonal changes in habitat use by houbara bustards Chlamydotis [undulata] macqueenii in northern Saudi Arabia. Ibis 141:20-215

Van Heezik Y, Saint Jalme M, Hémon S, Seddon P (2002) Temperature and egg-laying experience influence breeding performance of captive female houbara bustards. J Avian Biol 33:63-70

Verhulst S (1994) Supplementary food in the nestling phase affects reproductive success in pied flycatchers (Ficedula hypoleuca). Auk 111:714-716

White GC, Burnham KP (1999) Program MARK: survival estimation from populations of marked animals. Bird Study 46:S120-S139

Editorial responsibility: David Richardson, Norwich, UK
Wilson S, Martin K, Hannon SJ (2007) Nest survival patterns in willow ptarmigan: influence of time, nesting stage, and female characteristics. Condor 109:377-388

*Wingfield JC (1984) Influence of weather on reproduction. J Exp Zool 232:589-594

Zanette L, Clinchy M, Smith JN (2006) Food and predators affect egg production in song sparrows. Ecology 87: 2459-2467

Z Zann RA, Morton SR, Jones KR, Burley NT (1995) The timing of breeding by zebra finches in relation to rainfall in central Australia. Emu 95:208-222

Zuur A, Ieno EN, Walker N, Saveliev AA, Smith GM (2009) Mixed effects models and extensions in ecology with R. Springer, New York, NY

Submitted: April 25, 2017; Accepted: November 9, 2017 Proofs received from author(s): January 25, 2018 